\title{
Static priority scheduling of event-triggered real-time embedded systems
}

\author{
Cagkan Erbas · Andy D. Pimentel · Selin Cerav-Erbas
}

Published online: 5 October 2006

(C) Springer Science + Business Media, LLC 2006

Erratum to: Form Method Syst Des

DOI: $10.1007 / \mathrm{s} 10703-006-0021-2$

The online author listing in the HTML version and the online PDF unfortunately contained a typographical error. The author name of Andy D. Pimentel appeared twice and should have correctly appeared only once. The author list appears correctly in the printed version.

The online version of the original article can be found at http://dx.doi.org/10.1007/s10703-006-0021-2

C. Erbas $(\bowtie) \cdot$ A. D. Pimentel

Department of Computer Science, University of Amsterdam, 1098 SJ Amsterdam, The Netherlands e-mail: cagkan@science.uva.nl

\section{A. D. Pimentel}

e-mail: andy@science.uva.nl

S. Cerav-Erbas

School of Management, Université Catholique de Louvain, 1348 Louvain-la-Neuve, Belgium e-mail: cerav@poms.ucl.ac.be 